\title{
Corrosion protection of chromium-coated steel by hybrid sol-gel coatings
}

\author{
Ana F. Suzana ${ }^{\text {a }}$, Elivelton A. Ferreira ${ }^{\mathrm{a}, \mathrm{b}}$, Assis V. Benedetti ${ }^{\mathrm{a}}$, Hudson W.P. Carvalho ${ }^{\mathrm{a}, 1}$, \\ Celso V. Santilli a , Sandra H. Pulcinelli ${ }^{\text {a,* }}$ \\ a Universidade Estadual Paulista, Instituto de Química, Araraquara, SP, Brazil \\ b Universidade Federal Fluminense, Instituto de Ciências Exatas, Departamento de Química, Volta Redonda, RJ, Brazil
}

\section{A R T I C L E I N F O}

Article history:

Received 12 February 2016

Revised 28 April 2016

Accepted in revised form 30 April 2016

Available online 1 May 2016

\section{Keywords:}

Tetraethyl orthosilicate

Poly(methyl methacrylate)-co-

(trimethoxysilyl)propyl methacrylate

Chromium-coated steel

Corrosion

Hybrid coating

\begin{abstract}
A B S T R A C T
The aim of this study was to investigate the effect of the amount of tetraethyl orthosilicate (TEOS) on the corrosion protection of chromium-coated steel (CCS) by poly(methyl methacrylate)-co-(trimethoxysilyl)propyl methacrylate (PMMA-co-TMSM) coatings in aerated and unstirred solutions containing $2 \mathrm{wt} \% \mathrm{NaCl}$ and acetic acid, at $\mathrm{pH}$ around 3.5. The MMA/Si molar ratios in the hybrid materials were adjusted to 10,3 , and 1 by adding different amounts of TEOS, producing materials denoted PMMA-Sil-10, PMMA-Sil-3, and PMMA-Sil-1, respectively. Scanning electron microscopy (SEM) images showed that the PMMA-Sil-10 and PMMA-Sil-3 hybrid coatings were homogeneous. These hybrids were submitted to 21 days of submersion in the same solution used to perform the electrochemical measurements, and their structural profiles investigated. ${ }^{29} \mathrm{Si}$ NMR results showed that hydrolysis and condensation reactions took place during the immersion treatment and provided further reinforcement of the siloxane network, which could enhance protection against corrosion. Furthermore the synthesis method enabled the close control of the inorganic phase content of the PMMA- $\mathrm{RSiO}_{3 / 2}$ hybrids. Electrochemical analysis demonstrated that the PMMA-Sil-3 coating remained on the metallic substrate for a prolonged period, providing high protection against corrosion due to the controlled TEOS content of the hybrid material.
\end{abstract}

(c) 2016 Elsevier B.V. All rights reserved.

\section{Introduction}

A wide range of hybrid materials can be produced by the hydrolytic condensation of alkoxysilane $\left(\mathrm{RSi}\left(\mathrm{OR}^{\prime}\right)_{3}\right)$ precursors modified with a polymerizable $\mathrm{R}$ group such as epoxy, methacrylic and acrylic organofunctional species. For corrosion protection purposes, polysiloxane-based hybrid materials are of particular interest due to the dense structure of siloxane nodes cross-linked with polymeric methacrylate groups [1]. Tetraethyl orthosilicate (TEOS) is an alkoxysilane widely used, it has excellent corrosion protection and is the most efficient of this group.

The sol-gel route has been commonly used to prepare these hybrids coatings. In this process the alkoxysilane group is used as a coupling agent by providing covalent bonding between the organic coating and the metallic substrates. Under ideal conditions, co-condensation between $\mathrm{Si}-\mathrm{OH}$ and $\mathrm{M}-\mathrm{OH}$ results in a Si-O-M linkage [1,2]. The hydrolysis of alkoxysilanes has a dramatic effect on final properties of the sol-gel film. Usually, dipping method has been employed for application of hydrolyzed silane solution. The silanol groups interact themselves (intra-condensation) and it can interact also with the hydroxyl groups

\footnotetext{
* Corresponding authors.

E-mail addresses: anaflaviasuzana@yahoo.com.br (A.F. Suzana),

eliveltonalves@id.uff.com.br (E.A. Ferreira), sandrap@iq.unesp.br (S.H. Pulcinelli).

1 Present address: Centro de Energia Nuclear na Agricultura, Universidade de São Paulo, PO Box 96, Piracicaba, SP 13400-970, Brazil.
}

on the metal surface (inter-condensation) through temporary weak hydrogen bonding. The formation of strong covalent metal-siloxane bonds takes place during subsequent drying and curing [3,4]. A technological advantage of these materials arises from their ability to be produced at room temperature conditions on an industrial scale using wellestablished and low-cost methods [5,6]. Hence, a variety of substrates including bronze, copper, aluminum, magnesium alloys and stainless steels have been coated with these type of material [7-10].

The hybrid sol-gel coatings are complex matrices. The intermolecular interactions between the macromolecular existing structures and metallic surface are extremely relevant to material properties, such as low porosity, rigidity and adhesion to substrate. The conjugation of these interactions results in materials with enhanced protective properties against oxidation, corrosion and erosion [11].

Brusciotti et al. developed new hybrid coatings using four different silanes in order to protect a magnesium alloy from corrosion in $0.05 \mathrm{M}$ $\mathrm{NaCl}$ solution. The results show that the amino-propyltriethoxysilane (APTES) and aminopropyltrimethoxysilane (APTMS) formed a denser and better crosslinked hybrid coating, and showed a higher corrosion resistance than those reported in literature [6].

Liu et al. have described hybrid coatings based on copolycondensation of TEOS and (trimethoxysilyl)propyl methacrylate (TMSM) followed by the co-polymerization of methyl methacrylate (MMA) and triallyl isocyanurate (TAIC). The hybrid coatings were then deposited on tinplate and the corrosion behavior was studied. It was found that the hybrid coatings can significantly improve the 
protection against corrosion. The coating performance was attributed to the formation of a physical barrier based on the crosslinked network formed during the polycondensation reaction [12].

Polysiloxane hybrid sol-gel coatings were prepared using epoxy groups and aminosilanes via hydrolysis and polycondensation reaction of the silanol groups. The electrochemical analyses showed that the aminosilane-based hybrid coating (APTMS) exhibited excellent anticorrosion barrier properties in $3.5 \mathrm{wt} \% \mathrm{NaCl}$ medium [13].

According to Grundmeier et al. [14], the diffusion rates of $\mathrm{H}_{2} \mathrm{O}$ and $\mathrm{O}_{2}$ far exceed the diffusion limited value for oxygen reduction in the organic coatings used for corrosion protection. However, ion solubility within the coating is typically minimal, due to the low dielectric constants of common coatings. The corrosion protection provided by the coating is due to the creation of a barrier against chloride, acetate, and $\mathrm{H}^{+}$ions, leading to an extended diffusion layer, adhesion of the coating, and blocking of ionic paths between local anodes and cathodes along the metal/polymer interface.

Our group has been working on the development of PMMApolysilsesquioxane organic-inorganic hybrids, among others, which have been employed as protective coatings against the corrosion of different metallic substrates. The results have shown that these are promising materials for good corrosion protection of tinplate in chloride-based solution at $\mathrm{pH} 3.5$, due to the formation of a dense inorganic domains bonded by the polymeric chains [15-19]. In the present work, PMMA-RSiO ${ }_{3 / 2}$ hybrids with different silsesquioxane contents were employed as protective layers on commercial chromium-coated steel.

The chromium-coated steel consists of a thin gauge low carbon steel substrate with a thin coating, comprising a base layer of chromium metal and a top layer of chromium oxide, and used in the production of coatings for packaging steel [20]. This material is used in conjunction with an organic overcoat to provide corrosion resistance. Two mechanisms of corrosion are of primary concern: firstly, wet corrosion where the internal packaging surface is in contact with the package contents, and secondly, atmospheric corrosion of the external surface [21].

These PMMA-RSiO $3 / 2$ organic-inorganic covalently linked hybrids are built from polysilsesquioxane (PSQ) building blocks, with $\mathrm{RSiO}_{3 / 2}$ units as coupling agents, and present good thermal stability [22], although their anti-corrosive properties have not yet been tested. Two main points are addressed in this paper: i) the behavior of the hybrid coating in an acidic/saline medium, and ii) the effect of TEOS on corrosion protection.

\section{Materials and methods}

\subsection{Preparation of the organic-inorganic hybrids}

The procedure used to synthesize the organic-inorganic hybrids has been previously described [22]. Briefly, the first step of the procedure was the copolymerization of methyl methacrylate (MMA) and (trimethoxysilyl)propyl methacrylate (TMSM) in tetrahydrofuran (THF). This mixture was stirred under reflux, producing a PMMA-coPTMSM copolymer solution at molar proportion MMA:TMSM:10:1.

In a second step, the amount of the inorganic phase was adjusted to produce materials with MMA/Si molar ratios of 10,3 , and 1 (here denoted PMMA-Sil-10, PMMA-Sil-3, and PMMA-Sil-1, respectively), by adding $0,0.85$, or $1.70 \mathrm{~mL}$ of TEOS (Aldrich) to $15 \mathrm{~mL}$ of the asprepared PMMA-co-PTMSM solution. After 5 min under reflux and magnetic stirring at $55^{\circ} \mathrm{C}$, water acidified with $\mathrm{HNO}_{3}\left(\mathrm{pH} 1,\left[\mathrm{H}_{2} \mathrm{O}\right] /[\mathrm{Si}]\right.$ 3.5) was added to the reaction batch in order to start the hydrolysis and polycondensation reactions of the silyl groups. The stirring at $55{ }^{\circ} \mathrm{C}$ was stopped after $30 \mathrm{~min}$. From the resulting dispersion, selfsupported films were prepared by casting over Teflon ${ }^{\mathrm{TM}}$ plates, and thin films were prepared by dip-coating onto commercially available $0.15 \mathrm{~mm}$ thick CCS foil (SAE 1012 steel, CSN, Brazil).

\subsection{Substrate treatment and film deposition}

Before the electrochemical measurements, the CCS were cut into small plates $(2 \mathrm{~cm} \times 2 \mathrm{~cm})$, sonicated in acetone, and thoroughly rinsed with distilled water. These substrates were then dipped into the hybrid sol and withdrawn from the solution at a constant rate of $100 \mathrm{~mm} \mathrm{~min}^{-1}$. The resultant coated samples were dried and cured at $100{ }^{\circ} \mathrm{C}$ for $24 \mathrm{~h}$.

\subsection{Aging of the unsupported coating in acidic saline medium}

One goal of this work was to examine the structure of the hybrid material at the end of the experiment, i.e., after its exposure to a corrosive medium. The PMMA-Sil-10, PMMA-Sil-3, and PMMA-Sil-1 hybrid coatings, in their powder forms, were therefore maintained submerged for 21 days in the same solution used to perform the corrosion tests ( $2 \mathrm{wt} \% \mathrm{NaCl}$ and acetic acid, at $\mathrm{pH} \sim 3.5$ ). This immersion time was the same as the total immersion time during the electrochemical monitoring of the corrosion process. Afterwards, the aged hybrid samples were dried at $100^{\circ} \mathrm{C}$ for $24 \mathrm{~h}$, and analyzed by FTIR and NMR techniques.

\subsection{Surface and structural characterization}

SEM images of the surfaces and cross sections of the CCS plates coated with the PMMA-Sil-10, PMMA-Sil-3, and PMMA-Sil-1 hybrids were observed using low-vacuum scanning electron microscopy (LV-SEM) (JEOL 5900LV), after depositing a film of gold $~ 10 \mathrm{~nm}$ thick.

Atomic force microscopy (AFM) images were acquired with an Agilent AFM system Model 5500 (Agilent Technologies, Chandler, AZ, USA) in tapping mode in air using tip made of Si with Al coating on the back for reflection. Typical settings: tip curvature radius $<10 \mathrm{~nm}$, cantilever length $125 \mu \mathrm{m}$, width $30 \mu \mathrm{m}$, force constant $42 \mathrm{~N} \mathrm{~m}^{-1}$ and resonant frequency $320 \mathrm{kHz}$ (NCHR, Nanoworld). The AFM images (Phase and 3D topography images) were obtained using freely available software (Gwyddion V. 2.37). Cross-sectional images to measure the thickness of the film were acquired using a field emission scanning electron microscopy (FEI-Inspect F50).

Fourier transform infrared spectroscopy (FTIR) was used to measure the absorption spectra in the range $4000-400 \mathrm{~cm}^{-1}$. The measurements were performed with a Model 2000 spectrometer (Perkin Elmer), operated in transmission mode, using compressed $\mathrm{KBr}$ pellets containing $5 \mathrm{wt} \%$ of the powdered sample.

${ }^{29} \mathrm{Si}$ magic angle spinning nuclear magnetic resonance (MAS-NMR) spectra were recorded using a Varian Inova 300 instrument, at a frequency of $300 \mathrm{MHz}$ and magnetic field of 7.05 T. The Larmor frequency for ${ }^{29} \mathrm{Si}$ was $59.59 \mathrm{MHz}$. The chemical shifts were referred to tetramethylsilane, which was employed as an external standard, with the spectra obtained from free induction decays.

The FTIR and NMR measurements were performed for the as-dried powdered samples and for samples aged in the acidic solution containing $2 \mathrm{wt} \% \mathrm{NaCl}$ and acetic acid ( $\mathrm{pH} \sim 3.5)$.

\subsection{Electrochemical characterization}

The corrosion resistances of the PMMA-Sil-10, PMMA-Sil-3, and PMMA-Sil-1 hybrid coatings applied on the commercial CCS were evaluated using electrochemical impedance spectroscopy (EIS) in the corrosive, aerated and unstirred aqueous solutions containing $2 \mathrm{wt} \% \mathrm{NaCl}$ and acetic acid ( $\mathrm{pH} \sim 3.5$ ). Saline acidic solution, a typical electrolyte for studying the metal corrosion used in packaging, is corrosive to CCS $[19,20,23]$.

All the experiments were carried out using a conventional Tait-type three-electrode cell. The counter electrode was a Pt grid, and the potentials were referred to an aqueous $\mathrm{Ag} / \mathrm{AgCl} / \mathrm{KCl}_{\text {sat }}$ reference electrode connected to the working solution through a Luggin capillary. 
The solutions were prepared with analytical grade reagents and Milli-Q water $\left(18.2 \mathrm{M} \Omega \mathrm{cm}^{-1}\right)$. EIS measurements were carried out after exposing the metal coated with PMMA- $\mathrm{RSiO}_{3 / 2}$ to the electrolyte for different time intervals. The experiments were performed at $25^{\circ} \mathrm{C}$ over a frequency range from $100 \mathrm{kHz}$ to $10 \mathrm{mHz}$, with a sine wave amplitude of $10 \mathrm{mV}$ (rms) on the open circuit potential ( $\left.E_{O C P}\right)$, and recording 10 points per frequency decade. The measurements were conducted using an EG\&G potentiostat (Model 273A) coupled to a Solartron SI 1255 analyzer. Linear polarization curves were also obtained by scanning the potential interval from -10 to $+10 \mathrm{mV} v \mathrm{~s}$. $\mathrm{E}_{\mathrm{OCP}}$, at $0.167 \mathrm{mV} / \mathrm{s}$, after $2 \mathrm{~h}$ of immersion in the same solution used for the EIS experiments. For quantitative analysis, the EIS data were fitted using the equivalent electrical circuit (EEC) model using the Z-view ${ }^{\circledR}$ software.

In order to ensure reproducibility, a minimum of two runs were performed for each experiment.

\section{Results and discussion}

\subsection{Structural analysis}

The surface morphologies of the organic-inorganic hybrids were studied by SEM. Neither cracks, nor other microstructural defects on the surfaces of the continuous and homogeneous films, were observed on the surface view images of the samples coated with PMMA-Sil-10 and PMMA-Sil-3, as shown in Fig. 1. However, the sample coated with PMMA-Sil-1 showed the presence of bubble-like pores. A possible explanation for this could be that the water produced during the condensation reaction generated a new phase separated from the hybrid network, such as a colloidal system with water retained in the interstices of the gel phase. In this mechanism, the high proportion of silanol formed in the hydrolysis reaction of the PMMA-Sil-1 precursor resulted in the release of a greater amount of water as a byproduct of the condensation reaction. This water induced phase separation from the hydrophobic hybrid network and consequently increased the porosity of the coating. The presence of pores is undesirable because they provide pathways for diffusion of the solution to the steel surface. Fig. 1 also shows the conjugated view of the substrate, which is rough, and the deposited coating, where it can be seen the formation of a dense film of PMMA-Sil-10 and PMMA-Sil-3 hybrids. There was evidence of continuous channels through the PMMA-Sil-1 coating indicated by the arrow (see the channels sequence with different diameters in Fig. 1).

Fig. 2 illustrates, respectively, the 3D topographic and AFM phase angle contrast of (A) bare CCS and (B) PMMA-Sil-3 coated hybrid. The surface of bare CCS is very irregular while the coated CCS depicts a more homogeneous topography. The comparison of the Z-scales, which is about 3 times lower for the coated sample, revealed that the hybrid coating drastically reduced the high surface roughness of the bare CCS. This roughness is due to the many mechanical processing defects and inclusions. Fig. $2 \mathrm{C}$ presents the SEM cross section image of PMMA-Sil-3 hybrid evidencing a regular film thickness of about $2.8 \pm$ $0.3 \mu \mathrm{m}$.

Fig. 3 shows the FTIR spectra of the pristine (solid line) and aged (dashed line) powdered hybrid coatings. All the spectra showed characteristic bands of the PMMA polymer and $\mathrm{Si}-\mathrm{O}$ bonds resulting from solgel reactions involving the alkoxy groups of TMSM and TEOS [24]. A weak band at around $1630 \mathrm{~cm}^{-1}$ was attributed to $C=C$ bonds and
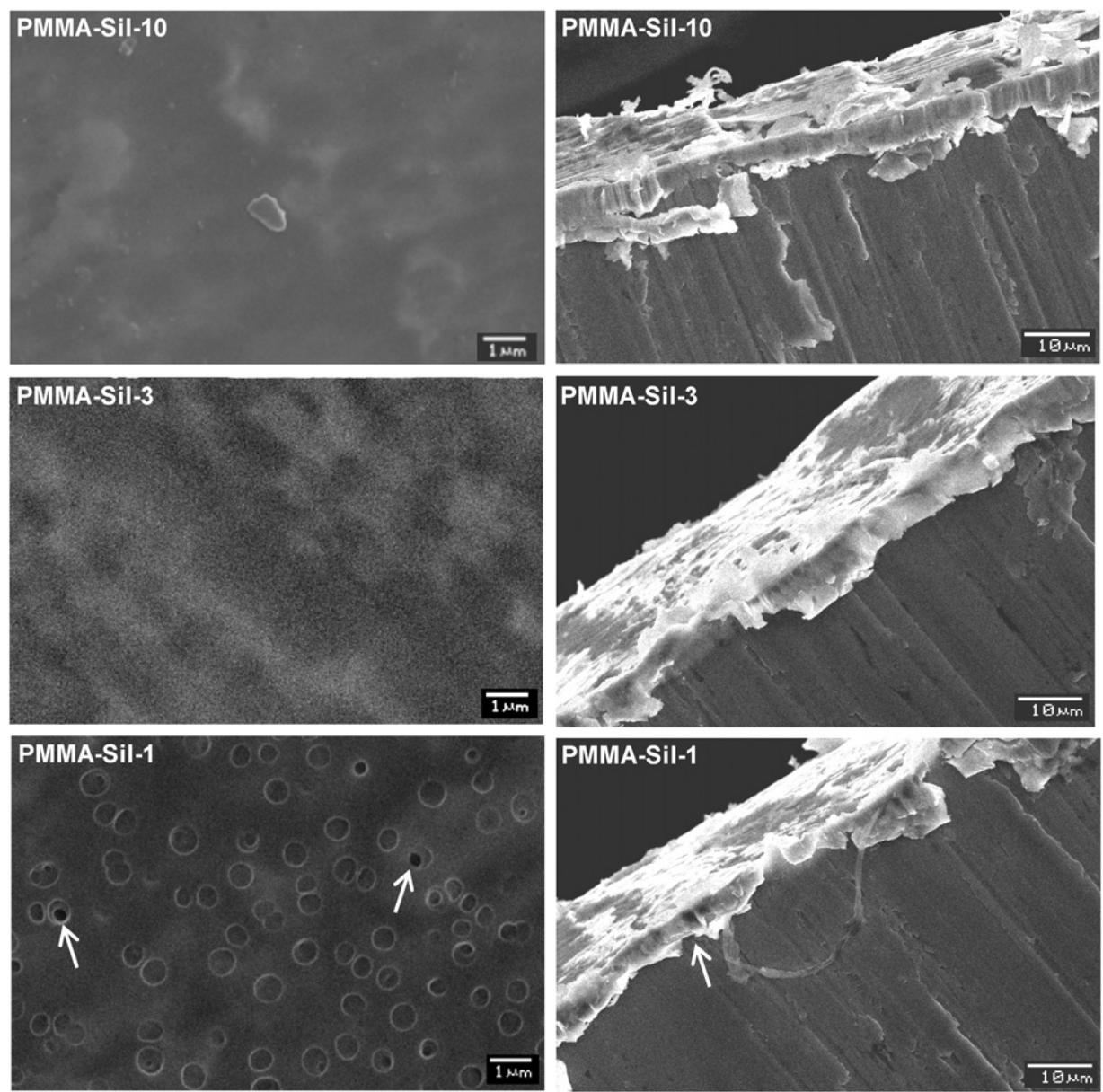

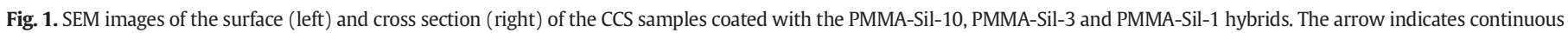
channels through the PMMA-Sil-1 coating. 


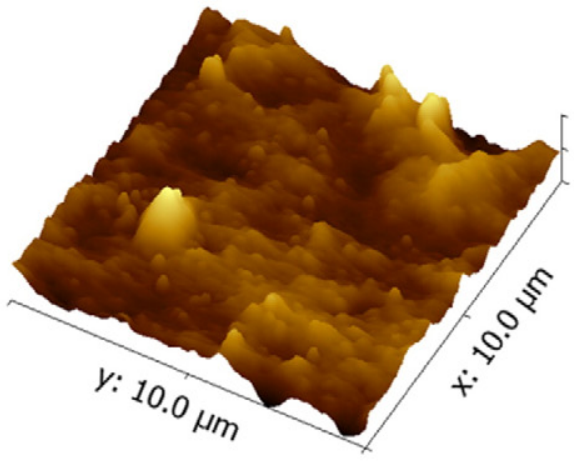

$0.26 \mu \mathrm{m}$

$0.00 \mu \mathrm{m}$

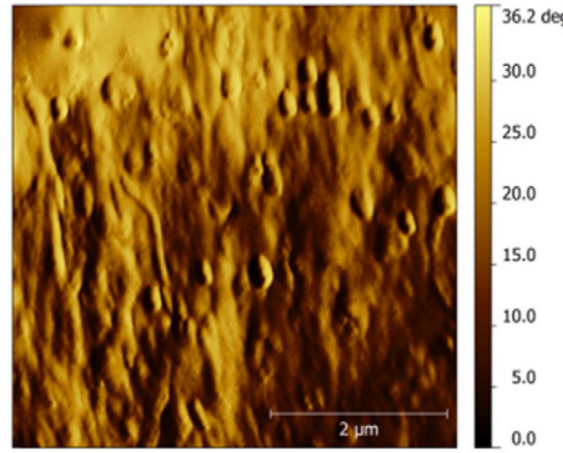

(A)
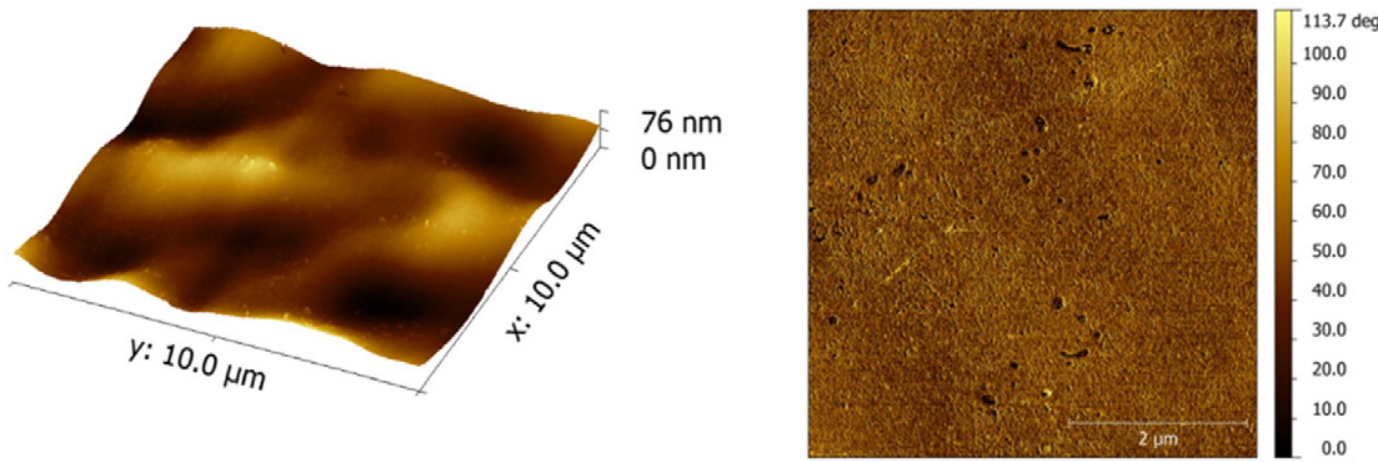

(B)

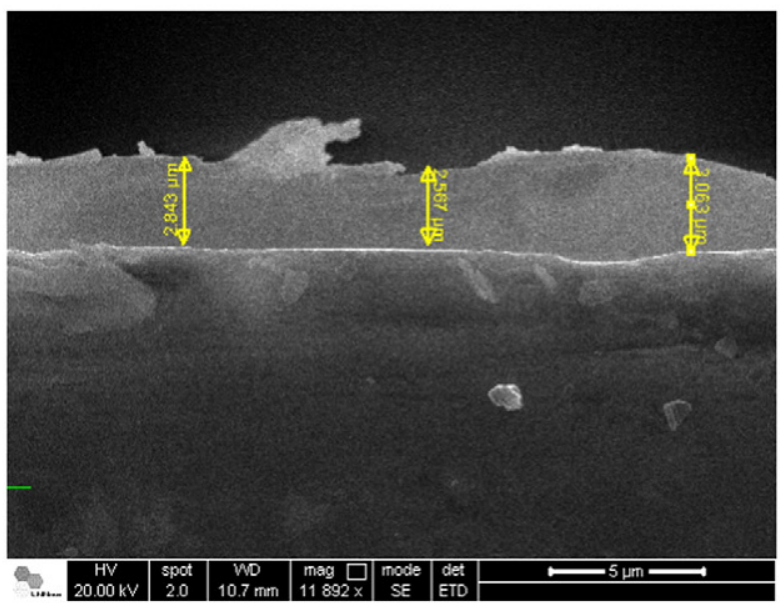

(C)

Fig. 2. AFM topographic and SEM images of samples: (A) 3D image of CCS bare and (B) PMMA-Sil-3 hybrid coated CCS; (C) SEM cross section of PMMA-Sil-3 hybrid coated CCS.

indicated that the PMMA contained unsaturated end chains [25]. Bands in the regions corresponding to $\mathrm{Si}-\mathrm{O}$ vibrations, at around $480 \mathrm{~cm}^{-1}$ and $580 \mathrm{~cm}^{-1}$ showed an increase in intensity with increasing of siloxane content, while the intensities of bands in the carbon region remained almost constant. The strong band at $1730 \mathrm{~cm}^{-1}$ was attributed to the carbonyl groups of PMMA.

The FTIR results showed that the vibrational spectra of the pristine and aged hybrid samples were virtually the same, indicating that the acidic saline solution did not attack the organic part of the coating (the PMMA chain). On the other hand, the relative intensity of the band at $480 \mathrm{~cm}^{-1}$, corresponding to Si-O-Si stretching, increased after exposure to the acidic saline solution for all samples, except PMMASil-3. This was indicative of the occurrence of hydrolysis and condensation reactions while the protective hybrid coating was immersed in the acidic saline solution.
Since infrared spectroscopy is not ideally suited to quantitative speciation analysis, the NMR technique was used for this purpose. Fig. 4 shows the ${ }^{29}$ Si NMR spectra of the pristine (solid line) and aged (dashed line) hybrids. The percentages of $T$ and $Q$ species present in each sample are given in Table 1. Tri-functional and tetra-functional silicon sites are defined using the $T^{x}, \mathrm{RSi}(\mathrm{OSi})_{x}(\mathrm{OH})_{3-\mathrm{x}}$ and $Q^{x}, \mathrm{Si}(\mathrm{OSi})_{\mathrm{x}}(\mathrm{OH})_{4-\mathrm{x}}$ notation. The $x$ represents the number of siloxane bonds composing each structure. The degree of condensation (\%DC) of the inorganic phase in the unsupported hybrid films was calculated from the relative proportions of each, $T^{x}$ and $Q^{x}$ species, calculated from the area of each peak, according to the following equation [26].

$\% \mathrm{DC}=\left[\left(T^{1}+2 T^{2}+3 T^{3}\right) / 3+\left(Q^{1}+2 Q^{2}+3 Q^{3}+4 Q^{4}\right) / 4\right] \times 100$ 


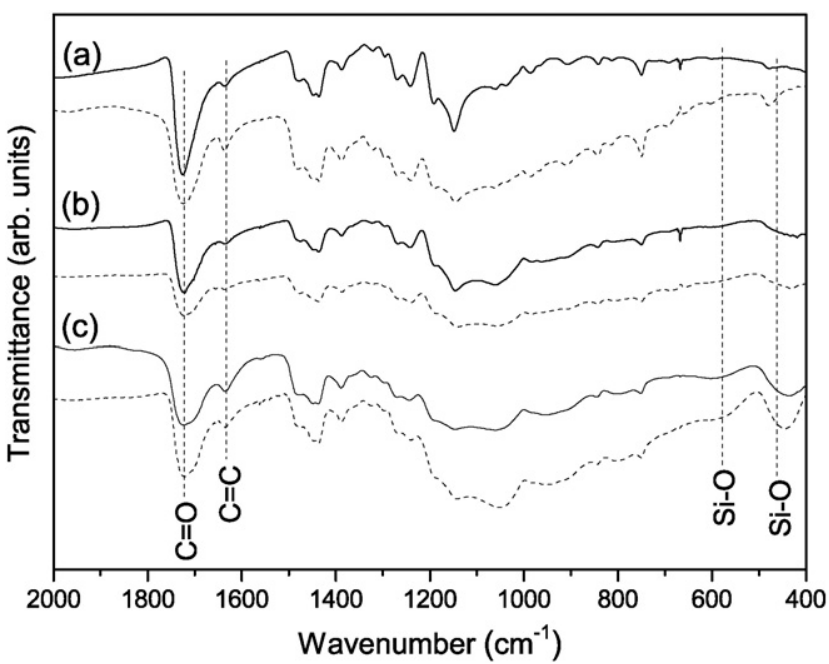

Fig. 3. FTIR spectra of the organic-inorganic hybrids before (solid line) and after (dashed line) 21 days of aging in acidic ( $\mathrm{pH}$ 3.5) solution: (a) PMMA-Sil-10, (b) PMMA-Sil-3, and (c) PMMA-Sil-1.

Before aging in the acidic saline solution, the \%DC values obtained for the PMMA-Sil-10, PMMA-Sil-3, and PMMA-Sil-1 hybrid coatings were $65.4,74.6$, and $78.3 \%$, respectively. These results show that the addition of TEOS favored the formation of more highly condensed silicon species ( $Q$ and $T$ ). Moreover, the $T$ and $Q$ speciation, shown in Table 1 , revealed substantial increases in the amounts of the most condensed species $\left(T^{3}\right.$ and $Q^{4}$ ) for the samples aged in the acidic saline solution. Consequently, the \%DC values increased significantly, demonstrating that the condensation reaction took place during aging. This phenomenon was observed by Sassi et al.[27], who used Raman spectroscopy to show that the hydrolysis and condensation reactions occurred progressively for several weeks, leading to the consumption of $T^{0}, T^{1}, Q^{1}$, and $Q^{2}$ species, and to the formation of a three-dimensional structure with more condensed species $\left(T^{3}\right.$ and $\left.Q^{4}\right)$. This finding indicated that the aqueous acidic solution environment was not aggressive towards the hybrid material; on the contrary, it improved the barrier properties due to densification of the coating. This behavior is promising for coatings damaged by localized corrosion.

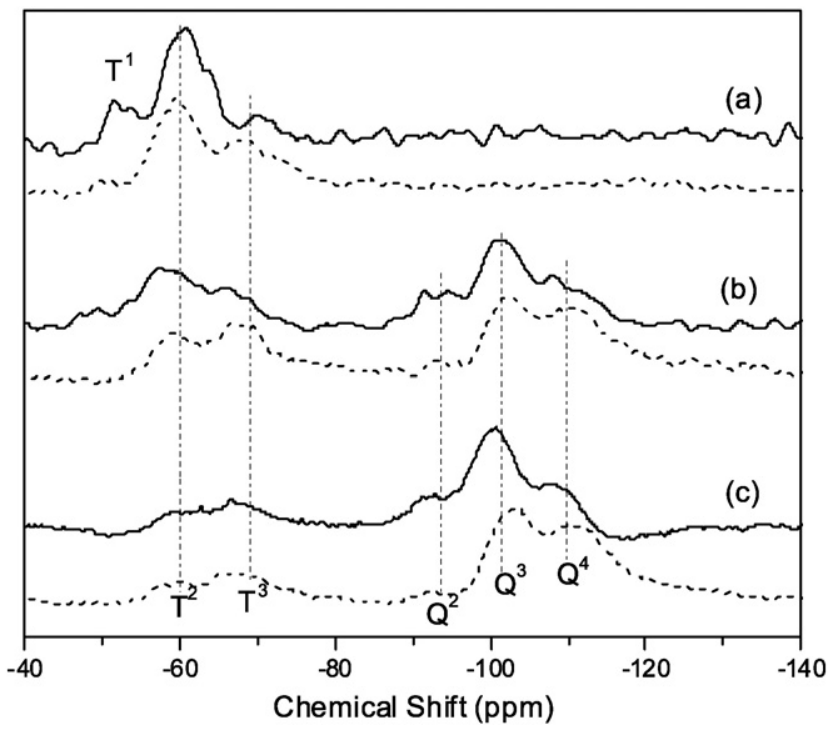

Fig. 4. ${ }^{29}$ Si MAS-NMR spectra of the organic-inorganic hybrids before (solid line) and after (dashed line) 21 days of aging in acidic ( $\mathrm{pH} \sim 3.5$ ) solution: (a) PMMA-Sil-10, (b) PMMASil-3, and (c) PMMA-Sil-1.
Table 1

Percentages of $T$ and $Q$ species and degree of condensation in the unsupported hybrid films, before and after aging in $2 \mathrm{wt} \% \mathrm{NaCl}$ acidic solution.

\begin{tabular}{lllllllll}
\hline Sample & $\begin{array}{l}T^{0} \\
(\%)\end{array}$ & $\begin{array}{l}T^{1} \\
(\%)\end{array}$ & $\begin{array}{l}T^{2} \\
(\%)\end{array}$ & $\begin{array}{l}T^{3} \\
(\%)\end{array}$ & $\begin{array}{l}Q^{2} \\
(\%)\end{array}$ & $\begin{array}{l}Q^{3} \\
(\%)\end{array}$ & $\begin{array}{l}Q^{4} \\
(\%)\end{array}$ & $\begin{array}{l}\text { Condensation } \\
\text { degree (\%) }\end{array}$ \\
\hline $\begin{array}{l}\text { PMMA-co-PTMSM } \\
\text { PMMA-Sil-10 }\end{array}$ & 68.0 & 18.0 & 14.0 & -- & -- & -- & -- & - \\
$\begin{array}{l}\text { PMMA-Sil-10+ } \\
\quad \text { acidic solution }\end{array}$ & -- & 14.7 & 74.6 & 10.7 & -- & -- & -- & 65.4 \\
$\begin{array}{l}\text { PMMA-Sil-3 } \\
\text { PMMA-Sil-3 + acidic }\end{array}$ & -- & 10.4 & 59.0 & 40.5 & -- & -- & -- & 80.0 \\
$\quad--$ & 1.6 & 36.2 & 62.2 & 4.9 & 41.3 & 53.8 & 87.2 \\
$\quad \begin{array}{l}\text { solution } \\
\text { PMMA-Sil-1 }\end{array}$ & -- & -- & 34.0 & 66.0 & 14.4 & 68.2 & 17.4 & 78.3 \\
$\quad$ solution & -- & 0.3 & 29.0 & 70.7 & 3.5 & 43.5 & 53.0 & 88.0 \\
\hline
\end{tabular}

\subsection{Corrosion evaluation of CCS and the hybrid coatings}

The corrosion potential and polarization resistance $\left(R_{p}\right)$ were evaluated after $2 \mathrm{~h}$ of immersion, and EIS diagrams were recorded for longer immersion times. Table 2 shows the parameters obtained from the linear polarization curves recorded for commercial CCS and for the hybridcoated samples after immersion for $2 \mathrm{~h}$. All the CCS substrates coated with hybrids presented similar corrosion potential values. The polarization resistance of PMMA-Sil-10 and PMMA-Sil-1 hybrid coatings is 3 times that of CCS while PMMA-Sil-3 presents the highest Rp, i.e., 40 times higher than the CCS.

These results demonstrated that the hybrid coatings were able to provide increased protection of CCS against corrosion, with PMMA-Sil3 showing the best performance after $2 \mathrm{~h}$ of immersion in aqueous acidic solution containing $2 \mathrm{wt} \% \mathrm{NaCl}$. In general, barrier coatings can protect the substrate according to two main mechanisms: a) resistance inhibition - the coating acts as an ionic filter with sufficiently high electrical resistance to mitigate charge transfer between anodic and cathodic sites; b) oxygen deprivation - suitably formulated coatings are able to exclude sufficient oxygen from the metal to impede the cathodic reaction [28]. Therefore, the lower corrosion potential measured for the hybrid-coated samples, as compared to the CCS substrate, can be explained by the oxygen deprivation mechanism. It has been shown that silicate-based films can decrease the rate of the cathodic reaction by limiting the diffusion of oxygen to the metal interface [28], and that polymers rich in hydroxyls have lower permeability to oxygen than nonpolar polymers [29].

The polarization resistance was also evaluated by EIS for different immersion times in $2 \mathrm{wt} \% \mathrm{NaCl}$ acidic aqueous solution. Fig. 5 shows the experimental and fitted impedance diagrams and Fig. 6 shows the equivalent electrical circuits (EECs) used to fit the experimental data.

For the bare CCS (Fig. 5A), two time constants were observed at 34 and $71 \mathrm{~h}$ of immersion: (a) one in the high frequency (HF) region, attributed to the chromium oxide top layer, and (b) one in the medium frequency (MF) domain, related to the interfacial process involving the underlying metallic substrate. For immersion times longer than $71 \mathrm{~h}$, the time constant associated with the chromium oxide layer disappeared or showed no more effect, due to dissolution of the layer in the electrolyte. When bare steel (without chromium coating) was used (Fig. 5A), only one time constant was detected, with the phase angle

Table 2

Corrosion potentials $\left(E_{\text {corr }}\right)$ and polarization resistance $\left(R_{p}\right)$ values for different samples after $2 \mathrm{~h}$ of immersion in $2 \mathrm{wt} \% \mathrm{NaCl}$ acidic solution.

\begin{tabular}{llc}
\hline Coatings & $\mathrm{E}_{\mathrm{corr}}(\mathrm{mV})$ & $\mathrm{R}_{\mathrm{p}}\left(\mathrm{k} \Omega \mathrm{cm}^{2}\right)$ \\
\hline CCS & $-400 \pm 100$ & $7 \pm 1$ \\
PMMA-Sil-10 & $-460 \pm 100$ & $26 \pm 6$ \\
PMMA-Sil-3 & $-460 \pm 100$ & $280 \pm 20$ \\
PMMA-Sil-1 & $-460 \pm 100$ & $26 \pm 4$ \\
\hline
\end{tabular}


(A)
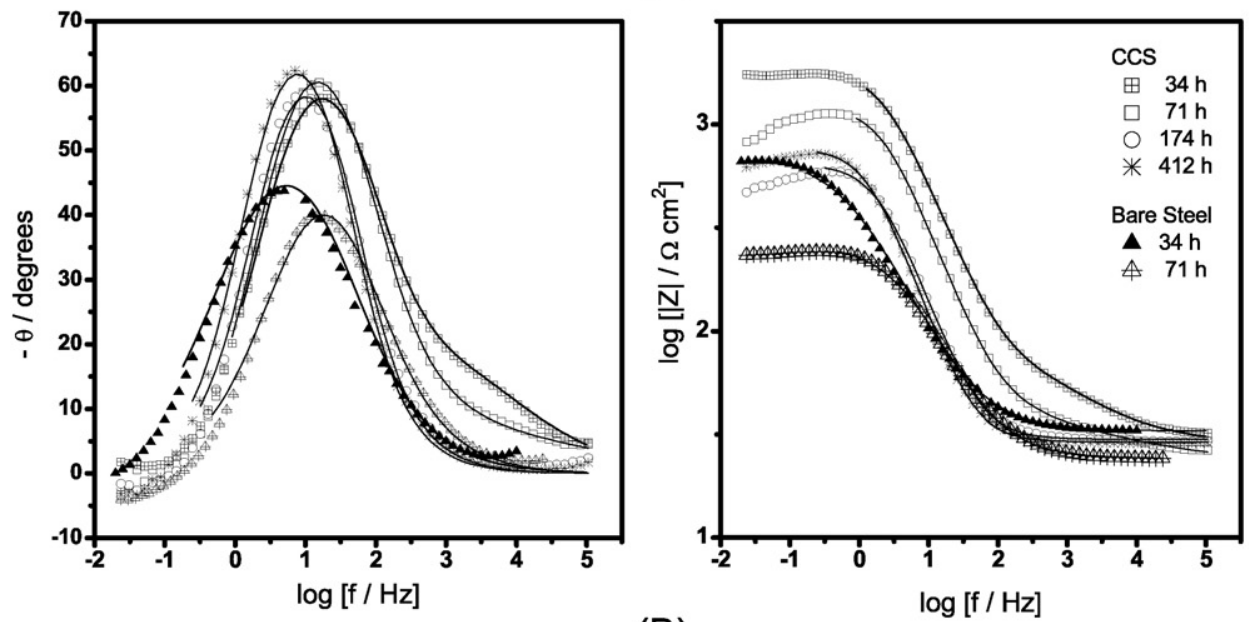

(B)
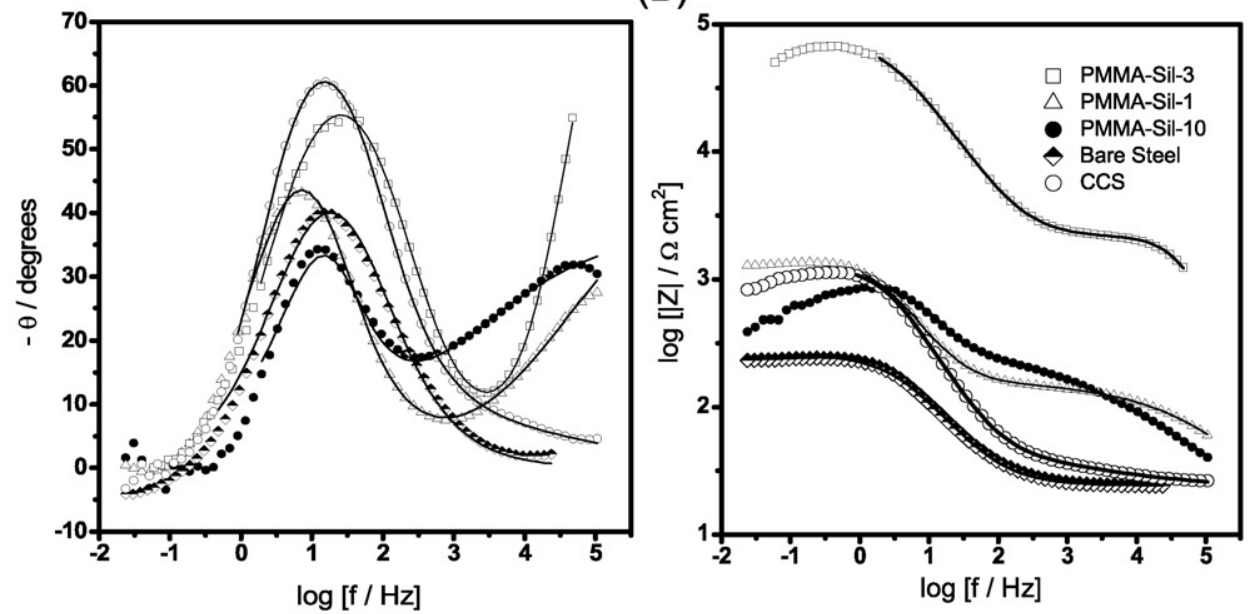

(C)
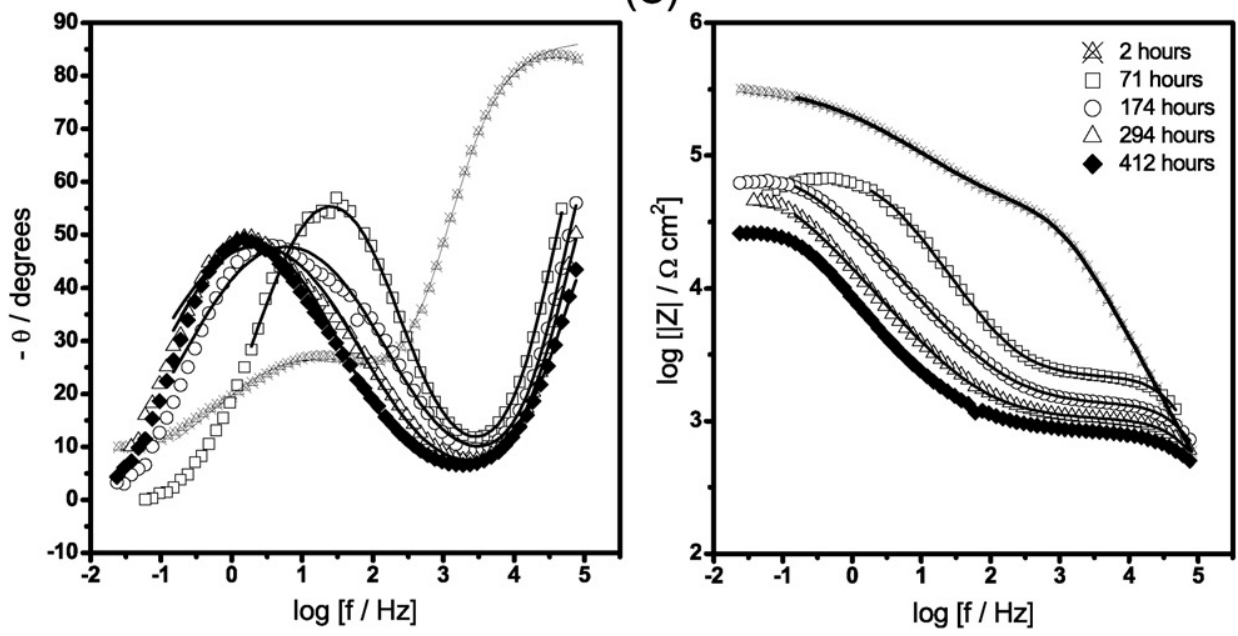

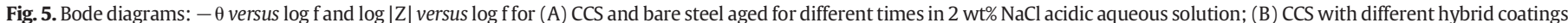

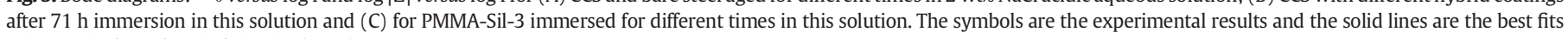
using equivalent electrical circuits (EECs).

located at $\sim 10 \mathrm{~Hz}$, and the impedance modulus at $0.022 \mathrm{~Hz}$ was $227 \Omega \mathrm{cm}^{2}$ at $71 \mathrm{~h}$. This impedance value was lower than that measured for the bare CCS at the same immersion time at $0.022 \mathrm{~Hz}\left(813 \Omega \mathrm{cm}^{2}\right)$. Moreover, the frequency region associated with the second time constant $(\sim 10 \mathrm{~Hz})$ for the bare steel was similar to that observed for CCS at $t \geq 174 \mathrm{~h}$ of immersion, confirming that the time constant at $\sim 10 \mathrm{~Hz}$ observed for CCS corresponds to the response of the underlying steel substrate. However, the phase angles associated with the second time constant (MF) for the bare steel and CCS were $-40^{\circ}$ and $-60^{\circ}$, respectively, and almost independent of the immersion time.

Fig. 5B shows the EIS diagrams obtained for the samples coated with the PMMA-Sil-3 hybrid films at $71 \mathrm{~h}$ of immersion. The EIS diagrams for CCS and bare steel are included for comparison while that concerning PMMA-Sil-10 and PMMA-Sil-1 are shown in Fig. 1S (supplementary 
(A)

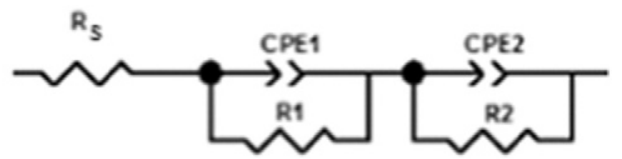

(B)

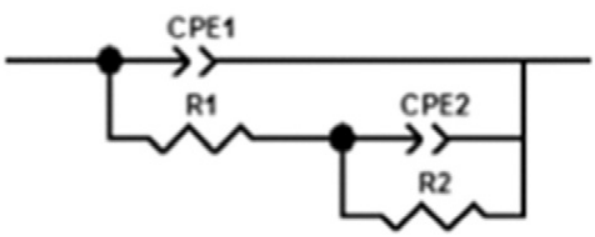

(C)

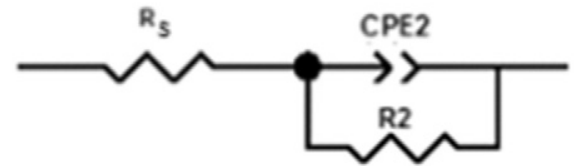

Fig. 6. Equivalent electrical circuits (EECs) used to fit the impedance data of the substrate (A) and coating for short (B) and long (C) immersion times in $2 \mathrm{wt} \% \mathrm{NaCl}$ acidic solution.

material) due to the similitude with the PMMA-Sil-3 one. In agreement with the $R_{p}$ results (Table 2), the sample coated with PMMA-Sil-3 showed the highest impedance value in the lower frequency range, indicating better resistance against corrosion $\left(47 \mathrm{k} \Omega \mathrm{cm}^{2}\right.$ at $0.05 \mathrm{~Hz}$ for $71 \mathrm{~h}$ of immersion). The Bode phase angle and the modulus of impedance diagrams showed two time constants, one at HF attributed to the response of the hybrid coating, and another in the MF region related to the interfacial processes (degradation of the chromium oxide layer and oxidation of the underlying steel). The phase angle of the time constant located in the HF region decreased in the following order: PMMASil-3 $\gg$ PMMA-Sil-10 > PMMA-Sil-1, in agreement with the SEM images (Fig. 1) that indicated greater porosity of PMMA-Sil-1. Samples PMMASil-10 and PMMA-Sil-3 were apparently free of microscopic porosity, and the PMMA-Sil-3 sample showed a greater degree of condensation, as indicated by the NMR measurements (Fig. 4 and Table 1). The time constant present in the MF region $(\sim 10 \mathrm{~Hz})$ appeared in the same frequency region for the CCS and the bare steel, indicating that this time constant was associated with interfacial processes. The time constant for the CCS was slightly shifted to higher frequencies, with higher phase angle compared to the bare steel, evidencing the passive character of the chromium oxide layer. The performance of the samples could also be evaluated by comparing the impedance modulus determined at low frequency $(0.05 \mathrm{~Hz})$ and $71 \mathrm{~h}$ of immersion: PMMA-Sil-3 $\left(47 \mathrm{k} \Omega \mathrm{cm}^{2}\right)$
》PMMA-Sil-1 $\left(1.3 \mathrm{k} \Omega \mathrm{cm}^{2}\right)>$ CCS $\left(0.81 \mathrm{k} \Omega \mathrm{cm}^{2}\right)>$ PMMA-Sil-10 $\left(0.35 \mathrm{k} \Omega \mathrm{cm}^{2}\right) \cong$ bare steel $\left(0.23 \mathrm{k} \Omega \mathrm{cm}^{2}\right)$. This is the answer of the last circuit element found when the frequency is analyzed from high to medium-low frequency region.

Fig. 5C shows experimental and fitted EIS diagrams for the PMMASil-3 coating in $2 \mathrm{wt} \% \mathrm{NaCl}$ acidic solution after different immersion times (between 71 and $412 \mathrm{~h}$ ). For all samples, the impedance decreased with immersion time (Table 3 ). For $t>71 \mathrm{~h}$, the PMMA-Sil-3 coating continued to protect the substrate, as indicated by the modulus of the impedance after $412 \mathrm{~h}$ of immersion $\left(|Z|=27.2 \mathrm{k} \Omega \mathrm{cm}^{2}\right)$, which is 30 times higher than for the bare CCS. It is important to highlight that even after 1 month of immersion in $2 \mathrm{wt} \% \mathrm{NaCl}$ acidic solution (not shown), a barrier effect was observed for the CCS samples coated with the PMMA-Sil-3 hybrid. On the other hand, samples coated with the PMMA-Sil-10 and PMMA-Sil-1 hybrid films showed corrosion behavior similar to the bare CCS (Table 3). In the case of the PMMA-Sil-10 coating, the non-protective behavior could have been due to the low \%DC of the coating, as a result of which the corrosion process was not hindered. The PMMA-Sil-1 coating showed pores formed during the sol-gel synthesis which favored generalized corrosion of the metallic layer and peeling of the hybrid coating as the immersion time increased.

For quantitative interpretation of the EIS results, the experimental data obtained for the hybrid-coated samples at different immersion times were fitted with the $Z$-view ${ }^{\circledR}$ program using the equivalent electrical circuits (EECs) shown in Fig. 6A, B and C. The heterogeneity of the studied systems resulted in non-ideal capacitive responses, so the socalled constant phase element (CPE) was used in place of the capacitance [30]. The continuous lines displayed in Fig. 5A, B and C show the results of the impedance data fitting for bare, CCS substrate and the coated PMMA-Sil-3 up to around $1 \mathrm{~Hz}$. The suitability of the proposed EECs is indicated by the sum of squared deviations $\left(\chi^{2}\right)$ value of around $10^{-3}$ (Table 3 ), the good agreement between the fitted and experimental EIS diagrams, as well as the coherence between the physical meaning of EECs parameters and the chemical characterization of the coatings. Regarding the relative standard errors of the parameters, according to Macdonald [31], if these values are of the order of $30 \%$ or more, the associated parameters are not well determined by the data and should be removed from the equivalent circuit. Generally, one would keep modifying the equivalent circuit and doing fitting until the above criteria are as well satisfied as possible. Under the general criterion of using as simple equivalent circuit with as few individual elements, a simplest EEC was used to fit the results. In this work, these procedures were adopted and acceptable relative standard errors were found (Table 3).

The fitting procedure revealed that two different EECs (shown in Fig. 6) were necessary to take into account the evolution of the EIS

Table 3

Values of EEC parameters obtained from the fitting of the experimental data for bare chromium-coated steel and the samples coated with different hybrid films.

\begin{tabular}{|c|c|c|c|c|c|c|c|c|c|c|}
\hline & Time (h) & $\mathrm{E}_{\mathrm{OCP}}^{\mathrm{a}}(\mathrm{mV})$ & $\mathrm{R}_{\mathrm{s}}\left(\Omega \mathrm{cm}^{2}\right)$ & $\mathrm{CPE}_{1}-\mathrm{T}\left(\mu \mathrm{F} \mathrm{cm}^{-2} \mathrm{~s}^{\alpha-1}\right)$ & $\mathrm{CPE}_{1}-\mathrm{P}$ & $\mathrm{R}_{1}\left(\mathrm{k} \Omega \mathrm{cm}^{2}\right)$ & $\mathrm{R}_{2}\left(\mathrm{k} \Omega \mathrm{cm}^{2}\right)$ & $\mathrm{CPE}_{2}-\mathrm{T}\left(\mu \mathrm{F} \mathrm{cm}^{-2} \mathrm{~s}^{\alpha-1}\right)$ & $\mathrm{CPE}_{2}-\mathrm{P}$ & $\chi^{2}\left(10^{-3}\right)$ \\
\hline \multirow[t]{2}{*}{ Bare Steel } & 34 & & $33(1.10)$ & - & - & - & $0.7(2.22)$ & $551(2.66)$ & $0.7(0.91)$ & 1.3 \\
\hline & 71 & -60 & $24(0.39)$ & - & - & - & $0.2(0.87)$ & $374(1.88)$ & $0.7(0.48)$ & 1.5 \\
\hline \multirow[t]{4}{*}{$\mathrm{CCS}$} & 34 & & $29(2.44)$ & $55(0.37)$ & $0.86(0.24)$ & $1.8(0.47)$ & $0.03(5.23)$ & $206(18.00)$ & $0.5(0.02)$ & 0.02 \\
\hline & 71 & -250 & $22(11.83)$ & $2740(22.00)$ & $0.3(7.02)$ & $0.03(11.48)$ & $1.1(0.54)$ & $77(0.70)$ & $0.8(0.26)$ & 0.1 \\
\hline & 174 & -150 & $29(0.45)$ & - & - & - & $0.6(1.11)$ & $174(1.88)$ & $0.9(0.45)$ & 6.6 \\
\hline & 412 & -120 & $29(0.30)$ & - & - & - & $0.7(0.75)$ & $192(1.14)$ & $0.9(0.28)$ & 0.5 \\
\hline \multirow[t]{2}{*}{ PMMA-Sil-10 } & 71 & -290 & - & $76(5.02)$ & $0.4(0.92)$ & $0.2(1.74)$ & 0.8 (1.67) & $35(5.77)$ & $0.9(1.29)$ & 0.5 \\
\hline & 412 & -190 & $25(0.18)$ & - & - & - & $0.1(0.89)$ & $2120(0.98)$ & $0.8(0.38)$ & 2.3 . \\
\hline \multirow[t]{5}{*}{ PMMA-Sil-3 } & 2 & -612 & - & $0.005(2.38)$ & $0.9(0.21)$ & $35.7(1.51)$ & $3.13 .7(1.34)$ & $1(1.89)$ & $0.5(1.02)$ & 0.8 \\
\hline & 71 & -160 & - & $0.004(11.32)$ & $0.9(0.94)$ & $1.6(0.68)$ & $58.0(1.65)$ & $1(1.91)$ & $0.8(0.42)$ & 0.9 \\
\hline & 174 & -280 & - & $0.004(16.29)$ & $0.9(1.31)$ & $1,0(0.96)$ & $68.2(2.57)$ & $8(1.71)$ & $\begin{array}{l}0.7 \\
0.6(0.58)\end{array}$ & 2.1 \\
\hline & 294 & -200 & - & $0.008(16.38)$ & 0.9 (1.39) & $0.8(0.83)$ & $59.7(4.13)$ & $25(1.55)$ & $0.6(0.60)$ & 2.1 \\
\hline & 412 & -320 & - & $0.035(17.21)$ & $0.8(1.63)$ & $0.6(0.78)$ & 30.0 (3.47) & $39(1.62)$ & $0.7(0.65)$ & 2.3 \\
\hline \multirow[t]{2}{*}{ PMMA-Sil-1 } & 71 & -310 & - & $11(5.60)$ & $0.51(0.83)$ & $0.1(0.47)$ & $1.3(1.05)$ & 93 (1.53) & $0.84(0.41)$ & 0.3 \\
\hline & 412 & -180 & $32(0.45)$ & - & - & - & $0.2(2.24)$ & $970(2.46)$ & $0.85(0.83)$ & 9.0 \\
\hline
\end{tabular}

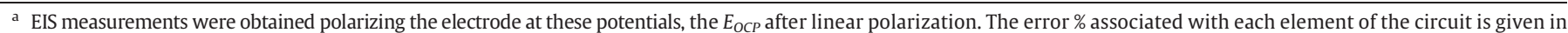
parenthesis. 
response of the hybrid-coated samples: one EEC with two time constants (Fig. 6B), and another with one time constant (Fig. 6C). In the circuit depicted in Fig. $6 B, \mathrm{R}_{1} / / \mathrm{CPE}_{1}$ and $\mathrm{R}_{2} / / \mathrm{CPE}_{2}$ are in parallel and correspond to the responses of the stratified coating structure (hybrid + passive oxide layer) and the underlying steel substrate, respectively. A value of CPE- $P=1$ corresponds to the response of an ideal capacitor $C$; $C P E-P=0.5$ suggests a diffusion response at low frequencies, or a porous material at high frequencies; and values of $0.5<\mathrm{CPE}-\mathrm{P}<1$ are associated with non-homogeneous current distributions [31,32] or heterogeneous distribution of the properties of the coating [33]. $R_{1}$ corresponds to the resistance of the conductive pathways through the hybrid coating and the chromium-iron oxide layer system, and $R_{2}$ is associated with the interfacial response of the underlying steel substrate, where the corrosion process takes place. The circuit depicted in Fig. 6A provided satisfactory fits to the EIS diagrams for the CCS sample for $t \leq 74 \mathrm{~h}$, which may correspond to an oxide layer with an axial distribution of dielectric and resistive properties [34]. The coating model shown in Fig. 6B has been used in many previous studies [6, 35-39]. The circuit depicted in Fig. 6C fits to the EIS diagrams for the CCS sample after $174 \mathrm{~h}$, PMMA-Sil-10 and PMMA-Sil-1 samples (Fig. 1S in supplementary material) after $412 \mathrm{~h}$ of immersion in $2 \mathrm{wt} \%$ $\mathrm{NaCl}$ acidic solution. The $\mathrm{CPE}_{2}-\mathrm{T}$ is related to the capacitance of the electrical double layer of the substrate/solution interface in parallel with the charge transfer resistance, $R_{2}$. The resistance $R_{2}$ is in series with the solution resistance, $R_{s}$.

Table 3 and Fig. 7 show the evolution of the passive elements of the EECs for the hybrid-coated samples at different immersion times. For the samples coated with hybrid films, both $R_{1}$ and $R_{2}$ decreased as the
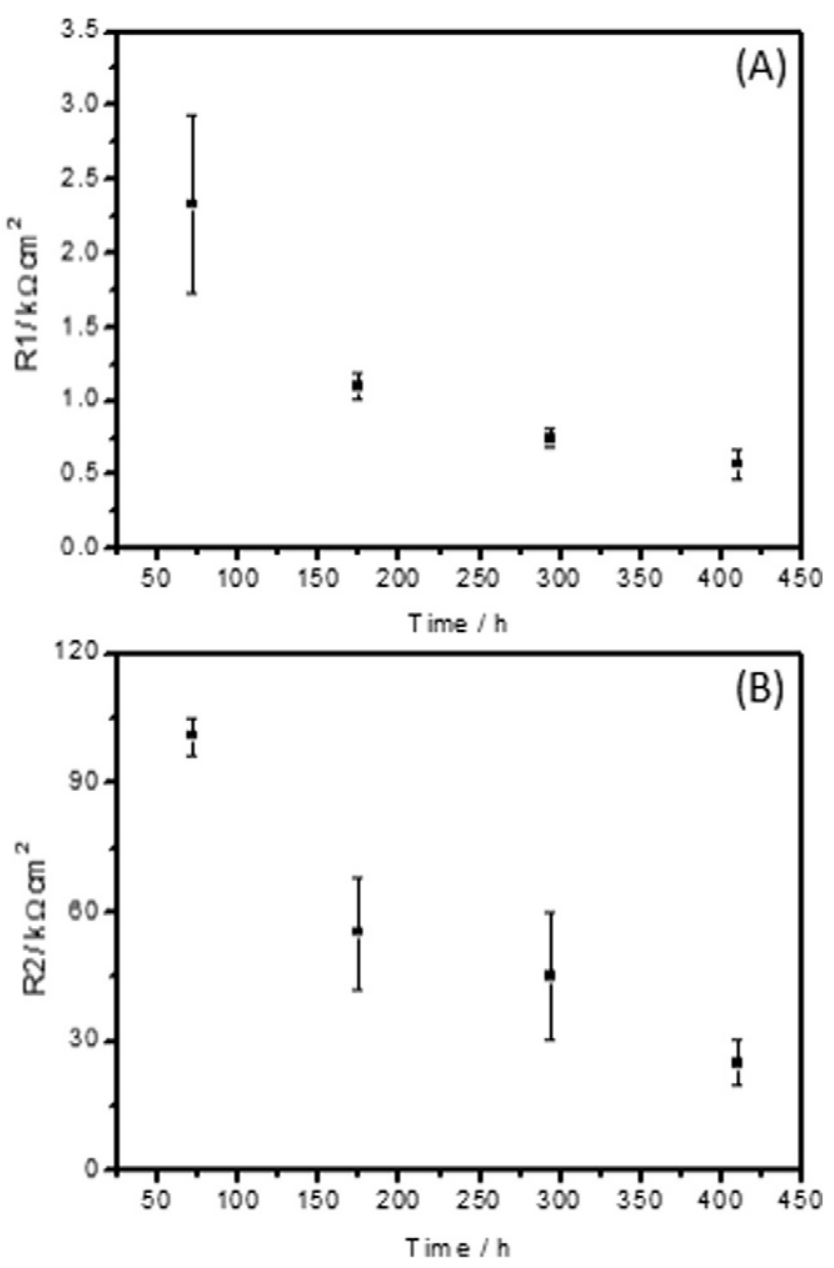

Fig. 7. Values of $R_{1}(A)$ and $R_{2}$ (B) obtained from the fitting of the experimental data for sample coated with PMMA-Sil-3 hybrid. immersion time increased. This suggests that the electrolyte easily reached the substrate and accelerated the corrosion process. On the other hand, $\mathrm{CPE}_{1}-\mathrm{T}$ and $\mathrm{CPE}_{2}-\mathrm{T}$ increased, indicating electrolyte uptake by the hybrid coating and an increase of the active area with immersion time. The EIS results obtained for the PMMA-Sil-10 and PMMA-Sil-1 coatings after $412 \mathrm{~h}$ were fitted with the EEC illustrated in Fig. 6C. The results showed that these coatings lost their protective properties due to the uptake of electrolyte by the hybrid coating and an increase of the active area with immersion time. Similar behavior was observed for the PMMA-Sil-3 coating, however, it is able to protect the substrate for long times. Fig. 7 shows the mean values of $R_{1}$ and $R_{2}$ with the respective deviations for PMMA-Sil-3 coating as a function of the immersion time. It is clearly seen the decrease of both $R_{1}$ and $R_{2}$ resistances values with time, but their values are much higher for PMMA-Sil-3 coating than for the other coatings.

The $\mathrm{E}_{\mathrm{OCP}}$ values tended to decrease for the PMMA-Sil-3 coating, and to increase for the PMMA-Sil-10 and PMMA-Sil-1 coatings and CCS (Table 3). Changes in the current density in the anodic and cathodic regions of the metallic surface, due to the inhibitory action/barrier effect of the coating, could have acted to modify the $\mathrm{E}_{\mathrm{OCP}}$ values of these samples with immersion time. For the bare CCS and the samples coated with the PMMA-Sil-10 and PMMA-Sil-1 hybrids, the increase in the $\mathrm{E}_{\mathrm{OCP}}$ values could have been due to greater transport of oxygen to the metallic surface after longer immersion times, which increased the cathodic current and the cathodic area on the metallic surface. For the sample coated with PMMA-Sil-3, the very low $\mathrm{E}_{\mathrm{OCP}}$ value observed after $2 \mathrm{~h}$ of immersion could have been related to oxygen deficiency on the electrode surface, while the decrease in the $\mathrm{E}_{\mathrm{OCP}}$ values for immersion times $>71 \mathrm{~h}$ could have been due to growth of the anodic area.

After $412 \mathrm{~h}$ of exposure to the electrolyte solution the PMMA-Sil-10 and PMMA-Sil-1 hybrids showed general corrosion of the metallic surface, while the sample coated with the PMMA-Sil-3 hybrid presented only small corroded regions.

The map of the elements of the coated material after $412 \mathrm{~h}$ of immersion (Fig. 2S, supplementary material) showed regions enriched in oxygen and poor in iron and chromium. These features indicated the formation of metal oxides at the CCS substrate/hybrid coating interface. On the other hand, the amounts of chlorine and carbon were practically constant on the entire surface of the sample.

\subsection{Mechanism of coating degradation and metal corrosion}

All the samples studied here presented corrosion of the CCS substrate after a certain time of immersion in $2 \mathrm{wt} \% \mathrm{NaCl}$ acidic solution, indicating that the electrolyte had reached the steel. This behavior can be explained by the presence of pores, structural defects, and the intrinsic permeability of the polymer phase of the hybrid coating. The permeation of ionic species through the hybrid film is associated with the free spaces between the polymeric chains in the amorphous PMMA phase. Moreover, porosity can be associated with macropores resulting from phase separation due to the formation of partially miscible liquid during the initial stages of the sol-gel transformation, as well as with the micropores of the inorganic part of the hybrid material $[38,40,41]$. Consequently, the electrolyte penetrates the hybrid coating and reaches the CCS, which has a porous chromium-iron oxide layer, and then arrives at the steel substrate. The acidic electrolyte attacks both the passive oxide layer and the metallic layer, leading to delamination of the hybrid coating after an immersion time that depends on the composition of the hybrid material.

For the samples coated with the PMMA-Sil-10 and PMMA-Sil-1 hybrids, the time constant at high frequency disappeared after $412 \mathrm{~h}$ of immersion in $2 \mathrm{wt} \% \mathrm{NaCl}$ acidic solution (Fig. 1S, supplementary material). In these cases, only the time constant at low/medium frequency was observed, which was associated with the corrosion of the substrate. This indicates that the PMMA-Sil-10 and PMMA-Sil-1 hybrid coatings were unable to act as hermetic barriers to electrolytes, probably due to the 
presence of micro- and macropores, respectively. On the other hand, under the same conditions, the sample coated with PMMA-Sil-3 still presented at least two time constants in the $-\theta v s$. log $\mathrm{f}$ diagrams (Fig. 5C), and no peeling of the coating was observed. For this hybrid coating, the addition of the alkoxysilane (in this case, TEOS) caused an increase in the degree of condensation (Table 1), favoring connectivity and densification of the inorganic hybrid network moieties, and consequently resulting in an effective barrier to electrolyte penetration. Moreover, the alkoxysilane acts as a coupling agent by providing covalent bonding between the organic coating and the metallic substrate, by means of a co-condensation mechanism between $\mathrm{Si}-\mathrm{OH}$ and metal$\mathrm{OH}$ [42].

Using the structural characterization and corrosion testing techniques employed in this work, it was possible to describe the formation of the hybrids and determine their effectiveness in protecting the metallic surface. The graphical abstract provides a schematic illustration of the structure of the hybrid material covering the surface of the metallic substrate (notably for the sample coated with PMMA-Sil-3, which provided the most effective barrier to diffusion, protecting the CCS from corrosion). After the hydrolysis and condensation reactions, the formation of a stable tridimensional network of siloxane groups linked with the polymeric phase ensured protection of the metallic surface by providing an effective barrier to chemical species that might attack the surface. This behavior was largely due to the siloxane phase formed after the addition of TEOS, which was characterized by a high crosslinking density, as shown by the degree of condensation calculated from the NMR measurements, as well as by the persistent adherence of the hybrid coating to the metallic surface.

\section{Conclusions}

The synthetic method presented in this work provided wellcontrolled structural properties of PMMA- $\mathrm{RSiO}_{3 / 2}$ hybrids, by means of the consistent regulation of the inorganic phase contents. The mild conditions of the sol-gel preparation process allowed the formation of adherent thin films by dip coating.

The spectroscopic results (FTIR and ${ }^{29} \mathrm{Si}$ NMR) showed that the organic phase was composed of the PMMA polymer, while the inorganic phase consisted of $\mathrm{T}$ and $\mathrm{Q}$ silicate species. For all the hybrids, the \%DC values were significantly improved after immersion in acidic solution, indicating that hydrolysis and condensation reactions had occurred. This finding indicates that in an aggressive medium, there was a tendency for the amounts of the most condensed species in the hybrids to increase, which is promising for coatings damaged by localized corrosion.

The electrochemical experiments revealed that the PMMA-Sil-3 coating provided the highest barrier protection against corrosion due to the consistent inclusion of TEOS in the hybrid material. The presence of TEOS increased the barrier properties of the hybrid coating, and therefore enhanced its potential for use as a corrosion protection barrier for metallic surfaces in aggressive environments.

\section{Acknowledgments}

The authors thank the funding agencies FAPESP (Process 2013/ 01078-3), CNPq (Process 305890/2010-7), FAPERJ (Process E-26/ 111.368/2014) for financial support, Prof. Dr. Ladário da Silva, LME/ UFF, Dr. Marina Magnani, IQ/UNESP, for technical assistance during the electron microscopy work, and National Nanotechnology Laboratory (LNNano) for granting access to the electron microscopy facilities.

\section{Appendix A. Supplementary data}

Supplementary data to this article can be found online at http://dx. doi.org/10.1016/j.surfcoat.2016.04.075.

\section{References}

[1] G. Kickelbick, Hybrid Materials: Synthesis, Characterization, and Applications, Wiley-WCH, Weinheim, 2007 442, http://dx.doi.org/10.1002/9783527610495.

[2] D. Wang, G.P. Bierwagen, Sol-gel coatings on metals for corrosion protection, Prog. Org. Coat. 64 (2009) 327-338, http://dx.doi.org/10.1016/j.porgcoat.2008.08.010.

[3] D. Balgude, A. Sabnis, Sol-gel derived hybrid coatings as an environment friendly surface treatment for corrosion protection of metals and their alloys, J. Sol-Gel Sci. Technol. 64 (2012) 124-134, http://dx.doi.org/10.1007/s10971-012-2838-z.

[4] W. Trabelsi, E. Triki, L. Dhouibi, M.G.S. Ferreira, M.L. Zheludkevich, M.F. Montemor, The use of pre-treatments based on doped silane solutions for improved corrosion resistance of galvanised steel substrates, Surf. Coat. Technol. 200 (2006) 4240-4250, http://dx.doi.org/10.1016/j.surfcoat.2005.01.044.

[5] R.B. Figueira, C.J.R. Silva, E.V. Pereira, Organic-inorganic hybrid sol-gel coatings for metal corrosion protection: a review of recent progress, J. Coat. Technol. Res. 12 (2015) 1-35, http://dx.doi.org/10.1007/s11998-014-9595-6.

[6] F. Brusciotti, D.V. Snihirova, H. Xue, M.F. Montemor, S.V. Lamaka, M.G.S. Ferreira, Hybrid-silane coatings for improved corrosion protection of Mg alloy, Corros. Sci. 67 (2013) 82-90, http://dx.doi.org/10.1016/j.corsci.2012.10.013.

[7] S.V. Lamaka, M.F. Montemor, A.F. Galio, M.L. Zheludkevich, C. Trindade, L.F. Dick, M.G.S. Ferreira, Novel hybrid sol-gel coatings for corrosion protection of AZ31B magnesium alloy, Electrochim. Acta 53 (2008) 4773-4783, http://dx.doi.org/10. 1016/j.electacta.2008.02.015.

[8] R.L. Twite, G.P. Bierwagen, Review of alternatives to chromate for corrosion protection of aluminum aerospace alloys, Prog. Org. Coat. 33 (1998) 91-100, http://dx.doi. org/10.1016/S0300-9440(98)00015-0.

[9] R.B. Figueira, C.J.R. Silva, E.V. Pereira, M.M. Salta, Ureasilicate hybrid coatings for corrosion protection of galvanized steel in cementitious media, J. Electrochem. Soc. 160 (2013) 467-479, http://dx.doi.org/10.1149/2.033310jes.

[10] F. Deflorian, S. Rossi, L. Fedrizzi, M. Fedel, Integrated electrochemical approach for the investigation of silane pre-treatments for painting copper, Prog. Org. Coat. 63 (2008) 338-344, http://dx.doi.org/10.1016/j.porgcoat.2008.03.005.

[11] R.B. Figueira, C.J.R. Silva, E.V. Pereira, Hybrid sol-gel coatings for corrosion protection of galvanized steel in simulated concrete pore solution, J. Coat. Technol. Res. 13 (2016) 355-373, http://dx.doi.org/10.1007/s11998-015-9751-7.

[12] J. Liu, L. Xu, Y. Fang, Hybrid organic-inorganic sol-gel coatings with interpenetrating network for corrosion protection of tinplate, J. Sol-Gel Sci. Technol. 71 (2014) 246-253, http://dx.doi.org/10.1007/s10971-014-3361-1.

[13] R. Suleiman, H. Dafalla, B. Ali, Novel hybrid epoxy silicone materials as efficient anticorrosive coatings for mild steel, RSC Adv. 5 (2015) 39155-39167, http://dx.doi. org/10.1039/C5RA04500B.

[14] G. Grundmeier, W. Schmidt, M. Stratmann, Corrosion protection by organic coatings: electrochemical mechanism and novel methods of investigation, Electrochim. Acta 45 (2000) 2515-2533, http://dx.doi.org/10.1016/S0013-4686(00)00348-0.

[15] P. Hammer, F.C. dos Santos, B.M. Cerrutti, S.H. Pulcinelli, C.V. Santilli, Highly corrosion resistant siloxane-polymethyl methacrylate hybrid coatings, J. Sol-Gel Sci. Technol. 63 (2012) 266-274, http://dx.doi.org/10.1007/s10971-011-2672-8.

[16] V.H.V. Sarmento, M.G. Schiavetto, P. Hammer, A.V. Benedetti, C.S. Fugivara, P.H. Suegama, S.H. Pulcinelli, C.V. Santilli, Corrosion protection of stainless steel by polysiloxane hybrid coatings prepared using the sol-gel process, Surf. Coat. Technol. 204 (2010) 2689-2701, http://dx.doi.org/10.1016/j.surfcoat.2010.02.022.

[17] P.H. Suegama, V.H.V. Sarmento, M.F. Montemor, A.V. Benedetti, H.G. de Melo, I.V. Aoki, C.V. Santilli, Effect of cerium (IV) ions on the anticorrosion properties of siloxane-poly(methyl methacrylate) based film applied on tin coated steel, Electrochim. Acta 55 (2010) 5100-5109, http://dx.doi.org/10.1016/j.electacta. 2010.04.002.

[18] S.V. Harb, B.M. Cerruti, S.H. Pulcinelli, C.V. Santilli, P. Hammer, Siloxane-PMMA hybrid anti-corrosion coatings reinforced by lignin, Surf. Coat. Technol. 275 (2015) 9-16, http://dx.doi.org/10.1016/j.surfcoat.2015.05.002.

[19] N. Wint, A.C.A. Vooys, H.N. McMurray, The corrosion of chromium based coatings for packaging steel, Electrochim. Acta (2016)http://dx.doi.org/10.1016/j.electacta.2016. 01.100 .

[20] B. Boelen, H. den Hartog, H. Weijde, Product performance of polymer coated packaging steel study of the mechanism of defect growth in cans, Prog. Org. Coat. 50 (2004) 40-46, http://dx.doi.org/10.1016/j.porgcoat.2003.09.011.

[21] E. Almeida, M.R. Costa, N. De Cristofaro, N. Mora, R. Catalá, J.M. Puente, J.M. Bastidas, Titanium passivated lacquered tinplate cans in contact with foods, Corros. Eng. Sci. Technol. 40 (2005) 158-164, http://dx.doi.org/10.1179/174327805X29859.

[22] H.W.P. de Carvalho, A.F. Suzana, C.V. Santilli, S.H. Pulcinelli, Synthesis, structure, and thermal stability of poly(methyl methacrylate)-co-poly(3-tri(methoxysilyil)propyl methacrylate)/montmorillonite nanocomposites, Polym. Degrad. Stab. 104 (2014) 112-119, http://dx.doi.org/10.1002/pen.23364.

[23] E. Almeida, M.R. Costa, N. Cristofaro, N. Mora, J.M. Bastidas, J.M. Puente, Environmentally friendly coatings for tinplate cans in contact with synthetic food media, J. Coat. Technol. Res. 1 (2004) 103-109, http://dx.doi.org/10.1007/s11998-0040004-4

[24] F. Namouchi, H. Smaoui, N. Fourati, C. Zerrouki, H. Guermazi, J.J. Bonnet, Investigation on electrical properties of thermally aged PMMA by combined use of FTIR and impedance spectroscopies, J. Alloys Compd. 469 (2009) 197-202, http://dx. doi.org/10.1016/j.jallcom.2008.01.148.

[25] L.E. Manring, Thermal degradation of poly(methyl methacrylate) 2. Vinylterminated polymer, Macromolecules 22 (1989) 2673-2677, http://dx.doi.org/10. 1021/ma00196a024.

[26] Y.H. Han, A. Taylor, M.D. Mantle, K.M. Knowles, UV curing of organic-inorganic hybrid coating materials, J. Sol-Gel Sci. Technol. 43 (2007) 111-123, http://dx.doi.org/ 10.1007/s10971-007-1544-8. 
[27] Z. Sassi, J.C. Bureau, A. Bakkali, Structural characterization of the organic/inorganic networks in the hybrid material (TMOS-TMSM-MMA), Vib. Spectrosc. 28 (2002) 251-262, http://dx.doi.org/10.1016/S0924-2031(01)00158-8.

[28] R.W. Revie, Uhlig's Corrosion Handbook, second ed. John Wiley \& Sons Inc., New York, 2000.

[29] N.L. Thomas, The barrier properties of paint coatings, Prog. Org. Coat. 19 (1991) 101-121, http://dx.doi.org/10.1016/0033-0655(91)80001-Y.

[30] J.R. Macdonald, Impedance Spectroscopy - Emphasizing Solid Materials and Systems, first ed. John Wiley \& Sons, New York, 1987.

[31] M. Cai, S.M. Park, Oxidation of zinc in alkaline solutions studied by electrochemical impedance spectroscopy, J. Electrochem. Soc. 143 (1996) 3895-3902, http://dx.doi. org/10.1149/1.1837313.

[32] R. Delevie, Fractals and rough electrodes, J. Electroanal. Chem. 281 (1990) 1-21, http://dx.doi.org/10.1016/0022-0728(90)87025-F.

[33] J.-B. Jorcin, M.E. Orazem, N. Pébère, B. Tribollet, CPE analysis by local electrochemical impedance spectroscopy, Electrochim. Acta 51 (2006) 1473-1479, http://dx.doi.org/ 10.1016/j.electacta.2005.02.128.

[34] M.E. Orazem, B. Tribollet, Electrochemical Impedance Spectroscopy, first ed. John Wiley \& Sons, New Jersey, 2008

[35] F. Mansfeld, M.W. Kendig, S. Tsai, Evaluation of corrosion behavior of coated metals with AC impedance measurements, Corrosion 38 (1982) 478-485, http://dx.doi. org/10.5006/1.3577363.
[36] M. Kendig, J. Scully, Basic aspects of electrochemical impedance application for the life prediction of organic coatings on metals, Corrosion 46 (1990) 22-29, http:// dx.doi.org/10.5006/1.3585061.

[37] P. Marcus, F. Mansfeld, Analytical Methods in Corrosion Science and Technology, first ed. CRC Press, Taylor \& Francis Group, New York, 2006.

[38] J.N. Murray, Electrochemical test methods for evaluating organic coatings on metals: an update. Part III: multiple test parameter measurements, Prog. Org. Coat. 31 (1997) 375-391, http://dx.doi.org/10.1016/S0300-9440(97)00099-4.

[39] R.T. Sakai, F.M. Di, L. da Cruz, H.G. de Melo, A.V. Benedetti, C.V. Santilli, P.H. Suegama, Electrochemical study of TEOS, TEOS/MPTS, MPTS/MMA and TEOS/MPTS/MMA films on tin coated steel in $3.5 \% \mathrm{NaCl}$ solution, Prog. Org. Coat. 74 (2012) 288-301, http://dx.doi.org/10.1016/j.porgcoat.2012.01.001.

[40] P.L. Bonora, F. Deflorian, L. Fedrizzi, Electrochemical impedance spectroscopy as a tool for investigating underpaint corrosion, Electrochim. Acta 41 (1996) 1073-1082, http://dx.doi.org/10.1016/0013-4686(95)00440-8.

[41] D.K. Ivanou, M. Starykevich, A.D. Lisenkov, M.L. Zheludkevich, H.B. Xue, S.V. Lamaka, M.G.S. Ferreira, Plasma anodized ZE41 magnesium alloy sealed with hybrid epoxysilane coating, Corros. Sci. 73 (2013) 300-308, http://dx.doi.org/10.1016/j.corsci. 2013.04.019.

[42] J. Huser, S. Bistac, M. Brogly, C. Delaite, T. Lasuye, B. Stasik, Investigation on the adsorption of alkoxysilanes on stainless steel, Appl. Spectrosc. 67 (2013) 1308-1314 http://dx.doi.org/10.1366/13-07073. 